Revue bibliographique pour le domaine irano-aryen

\title{
Barbara Kaim. "Women, Dance and the Hunt: Splendour and Pleasures of Court Life in Arsacid and Early Sasanian Art"
}

\section{Rémy Boucharlat}

\section{(2) OpenEdition}

Journals

Édition électronique

URL : http://journals.openedition.org/abstractairanica/46983

DOI : 10.4000/abstractairanica.46983

ISBN : 1961-960X

ISSN : 1961-960X

Éditeur :

CNRS (UMR 7528 Mondes iraniens et indiens), Éditions de l'IFRI

\section{Référence électronique}

Rémy Boucharlat, « Barbara Kaim. "Women, Dance and the Hunt: Splendour and Pleasures of Court

Life in Arsacid and Early Sasanian Art" », Abstracta Iranica [En ligne], Volume 37-38-39 | 2018,

document 64, mis en ligne le 30 décembre 2018, consulté le 28 septembre 2020. URL : http://

journals.openedition.org/abstractairanica/46983; DOI : https://doi.org/10.4000/abstractairanica. 46983

Ce document a été généré automatiquement le 28 septembre 2020.

Tous droits réservés 


\title{
Barbara Kaim. "Women, Dance and the Hunt: Splendour and Pleasures of Court Life in Arsacid and Early Sasanian Art"
}

\author{
Rémy Boucharlat
}

\section{RÉFÉRENCE}

Barbara Kaim. "Women, Dance and the Hunt: Splendour and Pleasures of Court Life in Arsacid and Early Sasanian Art" in V. Sarkhosh Curtis, E.J. Pendleton, M. Alram and T. Daryaee (eds.). The Parthian and Early Sasanian Empires: Adaptation and Expansion.

Proceedings of a Conference held in Vienna, 14-16 june 2012. Oxford \& Philadelphia: Oxbow, 2016, p. 90-105

L'A. passe en revue les représentations de personnages, des hommes, sans doute importants, peut-être même des portraits dans certains cas, et des femmes, quant à elles danseuses et musiciennes, dans certaines salles des résidences d'époque parthe et sassanide, royales (Nisa, Bishapur) ou princières (Qal'eh-i Yazdigird, Hajjiabad). L'illustration de scènes de banquets et de réjouissances ne fait pas de doute, mais l'utilisation de thèmes iconographiques dionysiaques, ainsi que d'autres motifs d'origine gréco-romaine (satyre, dieu Pan, ménades, etc.), posent un problème d'interprétation: ont-ils encore une signification religieuse? Dans ce cas, comment seraient-elles compatibles avec le zoroastrisme, si l'on considère par exemple la grande salle cruciforme de Bishapur comme un temple (Azarnoush, suivi par plusieurs savants, mais non par l'A)? Ne s'agit-il pas simplement de motifs décoratifs utilisés pour leur aspect, et peut-être leur sens, festifs? 


\section{AUTEURS}

\section{RÉMY BOUCHARLAT}

UMR 5133 CNRS-Université de Lyon 